Original article

\title{
The preferences of potential stakeholders in psychiatric genomic research regarding consent procedures and information delivery
}

\author{
Anna Sundby ${ }^{\mathrm{a}, \mathrm{b}, *}$, Merete Watt Boolsen ${ }^{\mathrm{c}}$, Kristoffer Sølvsten Burgdorf ${ }^{\mathrm{d}}$, Henrik Ullum ${ }^{\mathrm{d}}$, \\ Thomas Folkmann Hansen ${ }^{\mathrm{b}, \mathrm{e}, \mathrm{f}}$, Anna Middleton ${ }^{\mathrm{g}}$, Ole Mors ${ }^{\mathrm{a}, \mathrm{b}}$ \\ a Psychosis Research Unit, Aarhus University, Risskov, Denmark \\ ${ }^{\mathrm{b}}$ The Lundbeck Foundation Initiative for Integrative Psychiatric Research, iPSYCH, Denmark \\ ${ }^{\mathrm{c}}$ Department of Political Science, University of Copenhagen, Denmark \\ d Department of Clinical Immunology, Copenhagen University Hospital, Rigshopitalet, Denmark \\ e Institute for Biological Psychiatry, Mental Health Centre Sct. Hans, Copenhagen University Hospital, Copenhagen, Denmark \\ ${ }^{\mathrm{f}}$ Danish Headache Center, Department of Neurology, Rigshospitalet-Glostrup, Denmark \\ ${ }^{g}$ Society and Ethics Research, Connecting Science, Wellcome Genome Campus, Cambridge, United Kingdom
}

\section{A R T I C L E I N F O}

\section{Article history:}

Received 12 July 2018

Received in revised form 18 September 2018

Accepted 18 September 2018

Available online 29 October 2018

\section{Keywords:}

Mental disorder

Genetics

Ethics and human rights

Incidental findings

Informed consent

\begin{abstract}
A B S T R A C T
Background: Genomic sequencing plays an increasing role in genetic research, also in psychiatry. This raises challenges concerning the validity and type of the informed consent and the return of incidental findings. However, no solution currently exists on the best way to obtain the informed consent and deliver findings to research subjects.

Aims: This study aims to explore the attitudes among potential stakeholders in psychiatric genomic research toward the consenting procedure and the delivery of incidental findings.

Methods: We developed a cross-sectional web-based survey among five groups of stakeholders. A total of 2637 stakeholders responded: 241 persons with a mental disorder, 671 relatives, 1623 blood donors, 74 psychiatrists, and 28 clinical geneticists.

Results: The stakeholders wanted active involvement as $92.7 \%$ preferred a specific consent and $85.1 \%$ wanted to receive information through a dynamic consent procedure. The majority of stakeholders preferred to receive genomic information related to serious or life-threatening health conditions through direct contact (69.5\%) with a health professional, i.e. face-to-face consultation or telephone consultation (82.4\%). Persons with mental disorders and relatives did not differ in their attitudes from the other stakeholder groups.

Conclusion: The findings illustrate that the stakeholders want to be more actively involved and consider consent as a reciprocal transaction between the involved subjects and the researchers in the project. The results highlight the importance of collaboration between researchers and clinical geneticists as the latter are trained, through their education and clinical experience, to return and explain genomic data to patients, relatives, and research subjects.
\end{abstract}

(c) 2018 Elsevier Masson SAS. All rights reserved.

\section{Introduction}

Mental disorders have considerable consequences for those affected, for their families and for society in general. Our knowledge of the etiology and pathology of these disorders is very scarce. Nevertheless, our understanding of mental disorders has increased over time. Genetic research has contributed to this

\footnotetext{
* Corresponding author at: Department of Political Science, University of Copenhagen, Øster Farimagsgade 5, 1353 Copenhagen K, Denmark.

E-mail address: anna.sundby@ifs.ku.dk (A. Sundby).
}

enhanced understanding, which has developed from initially being based on adoption and twin studies and into molecular genetic research as genomic sequencing, including whole exome and whole genome sequencing [1-4]. Genomic sequencing is used in psychiatric genetic research to identify genetic variants that contribute to development of severe mental disorders [5]. The data are usually analyzed for genetic differences between case and control groups [6]. However, genomic sequencing produces detailed genotype information at high resolution, which holds the potential to facilitate individual clinical findings [7].

Using genomic sequencing in research challenges the current approach to informed consent and the return of incidental findings 
to research subjects [7-15]. International agreements and standards of ethical conduct, such as the Declaration of Helsinki, have mainly focused on protecting individuals from the potential dangers of participating in research and obtaining full informed consent from research subjects [16,17]. Informed consenting is the process where potential research subjects are informed about the research and potential risks of harm in order to prepare for making a reasoned decision on participation and whether they want to receive (individual) findings [9,18-22]. The traditional model for informed consent in genetic testing is derived from clinical genetics. Researchers have expressed that the traditional model needs to be adjusted to meet the challenges raised by the new era of genomic sequencing $[6,23]$. Several consent models exits. For example the consent is categorized as 'specific' when provided for an explicit research purpose, whereas a 'dynamic' consent entails a specific consent with active opt-in requirements for each research study $[7,20]$. However, there is still no consensus on the best way to obtain consent for genomic research.

In general, researchers do not provide access to the findings for research participants [24]. However, in recent years, many concerns have been raised concerning participants' right to receive research findings, specifically which findings should be returned to research participants [25-31]. Nevertheless, little attention has been directed towards exploring the best ways of obtaining informed consent and delivering research findings to participants. These issues need to be considered when collecting informed consent for research.

Returning findings from genomic research can be beneficial for the research participants but it may also be harmful if e.g. the research participant becomes anxious or makes irrational decisions because of the received results. Therefore, it is important to consider how to best report findings back to participants. This challenge is especially relevant in research on mental disorders, where the research participants must often cope with a disorder that influences both mood and cognition. More knowledge about the attitudes and preferences of stakeholders in psychiatric genomic research is needed in order to identify the consenting procedures and return strategies that consider these stakeholders' perspective and meet their interests. Here, we report a study on the attitudes among stakeholders in psychiatry towards consenting procedures and preferences concerning delivery of genomic research findings.

\subsection{Aims}

This study aims to explore the attitudes towards consenting procedures and delivery of incidental findings in five different groups of stakeholders in psychiatric genomic research: persons with a mental disorder, relatives to persons with a mental disorder, healthy individuals (participants in the Danish Blood Donor Study, forward referred to as blood donors), psychiatrists, and clinical geneticists.

\section{Methods}

\subsection{Research design}

We conducted a cross-sectional study to explore the attitudes in five groups of stakeholders in Denmark towards the use of genomic research.

\subsection{Data collection}

Data were collected in a web-based survey. The survey was a translated and modified version of an English web-based survey developed at the Welcome Trust Sanger Institute in Cambridge, United Kingdom [29,29,32,33]. Ten explanatory video films with subtitles and voice-over were used to illustrate the ethical issues raised in the survey. Details of the development of the English survey and the Danish survey have been presented elsewhere $[30,32,34]$. The data collection began on 12 August 2014 and ended on 17 April 2015. It took approximately 23 min in average to complete the survey. A number of pilot tests were performed before the data collection started. After each pilot test, the survey was revised in accordance with the findings in the pilot testing.

\subsection{The stakeholders}

We recruited five groups of stakeholders in psychiatric genomic research: (i) 1623 blood donors from the Danish Blood Donor Study $[35,36]$, who serve as potential healthy controls in genomic research; (ii) 241 persons with a mental disorder, representing potential cases in genomic research; (iii) 671 relatives to individuals with a mental disorder, representing potential controls in genomic research; (iv) 28 clinical geneticists, who analyse, return, and explain genomic data to patients and relatives in their clinical work, and who must validate genomic sequence findings obtained in research; and (v) 74 psychiatrists, who diagnose and treat people with mental disorders.

The stakeholders were recruited through links at the homepages of the Danish Psychiatric Association, the Danish Society of Medical Genetics, through user groups for psychiatric patients and their relatives, and through direct emails, paper flyers at psychiatric hospitals, and invitations posted in an ADHD Facebook group.

There were 4174 hits on the website for the survey, whereas 2637 completed the entire survey. The design of the web-based survey did not provide details on the non-response rate. A completion rate of $63 \%$ was achieved; estimated as the number of completed surveys divided by the number of hits.

\subsection{Statistical analysis}

We used descriptive statistics to characterize the study sample. Unadjusted associations between items and stakeholders were estimated using $\chi^{2}$ tests. A binary logistic regression model was used to estimate the association between attitudes toward consenting procedures and stakeholder groups. Estimates were adjusted for parenthood, gender, age, educational level, and marital status, with 95\% confidence interval (CI) and a p-value of 0.05 . The group of blood donors served as reference group, and "don't know" responses were omitted from the model. Blood donors were chosen as reference group as they are potential healthy controls in genomic research. We analyzed the data using SAS $^{\circledR}$ software, version 9.4 [37].

\subsection{Ethical considerations}

All participation in the project was voluntary. The participants received information in writing (survey introduction) about the project. Survey responses were anonymous, and implied consent was assumed when the stakeholders chose to answer the questions in the survey. The project was approved by the Danish Data Protection Agency (file no. 2007-58-015). The Committee on Health Research Ethics in the Capital Region of Denmark reviewed the project description and concluded that the study did not require ethical approval (file no. $\mathrm{H}$ 4_2013_FSP-051). As all data were based on anonymous information, no other ethical clearance was required for this type of study according to Danish law. 


\section{Results}

\subsection{Sample characteristics}

We report the distribution of sociodemographic characteristics by stakeholder group in Table 1. A total of 2637 individuals completed the survey. A few more females (52.7\%) than males (47.3\%) completed the survey. A higher proportion of the stakeholders were aged 41-60 years (52.4\%), had a long higher education (34.5\%), was married/cohabiting (66.9\%), and had no children (53.4\%). No statistically significant differences were found between the stakeholder groups for having children.

We found that only $5.2 \%$ reported to have had a genetic test or a genomic analysis performed. A total of $25.1 \%$ reported to be participants in a biobank. Psychiatrists were significant less likely to participate in a biobank than the four other stakeholder groups, which was distributed in the following way: blood donors (27.6\%), persons with a mental disorder (12.9\%), relatives (25.1\%), clinical geneticists (21.4\%), and psychiatrists (9.5\%). Only $10 \%$ of the stakeholders reported that they or a member of their family have participated in a genetic research project (Table 2 ).

\subsection{Attitudes toward consent procedure}

We explored the attitudes toward the informed consent procedure. A large majority (92.7\%) of the stakeholders wanted the research participant to have agreed to the specific aim of a study. In total, $85.1 \%$ preferred a dynamic consent procedure, where research participants could state (and regularly update) which type of information they would like to receive. However, psychiatrists were significantly less likely than blood donors to hold this view $(\mathrm{OR}=0.42)$ (Table 3$)$.

\subsection{Attitudes toward delivery of genomic information}

To gain a deeper understanding of the attitudes to genomic information, we asked the stakeholders how they would like to receive information about serious/life-threatening conditions and non-serious/not-life-threatening conditions. A total of $69.5 \%$ reported that they would like to receive genomic information related to serious or life-threatening conditions through direct contact (Table 4). When we asked how the direct contact should be delivered, $82.4 \%$ reported to prefer a face-to-face or telephone consultation with a health professional (data not shown).

Almost half of the stakeholders (47.9\%) reported that they would like to receive genomic information related to non-serious or non-life-threatening conditions via indirect contact. Persons with mental disorders, relatives and psychiatrists did not differ in their attitudes from blood donors. Clinical geneticists (21.4\%) were less interested in indirect contact than the four other stakeholder groups. Clinical geneticists reported to prefer direct contact (53.6\%) (Table 4). When we asked how indirect contact should be delivered, a total of $84.5 \%$ reported that they preferred it to be provided through a secure online database (data not shown).

\section{Discussion}

\subsection{Informed consent: a difficult necessity}

The result from this study illustrate that the stakeholders generally agreed that research participants should formally accept the specific aim of the study with a dynamic consent procedure that allowed permitting research subjects to change which findings they would like to receive.

The model of dynamic consent is based on the idea that genomic sequencing increases the possibility of producing valuable data, which the research subject should have access to, and that the research subject should be continuously informed about new findings in the data and have the choice to receive such new information [13]. Therefore, dynamic consent offers opportunities for ongoing communication between the research project and research subject. In this particular study, the stakeholders reported to prefer a model of informed consent that allowed the specific research activity and allowed the interests of the

Table 1

Socioeconomic characteristics of the five stakeholder groups.

\begin{tabular}{|c|c|c|c|c|c|c|c|}
\hline & $\begin{array}{l}\text { Blood donors }^{\mathrm{a}} \\
(\mathrm{n}=1623)\end{array}$ & $\begin{array}{l}\text { Persons with mental disorder } \\
(\mathrm{n}=241) \\
\%(\mathrm{n})\end{array}$ & $\begin{array}{l}\text { Relatives }^{\mathrm{a}} \\
(\mathrm{n}=671)\end{array}$ & Clinical geneticists $(n=28)$ & $\begin{array}{l}\text { Psychia- } \\
\text { trists }^{\mathrm{a}} \\
(\mathrm{n}=74) \\
\%(\mathrm{n})\end{array}$ & $\begin{array}{l}\text { Total }^{\mathrm{a}} \\
(\mathrm{n}=2637) \\
\%(\mathrm{n})\end{array}$ & P-value ${ }^{b}$ \\
\hline Sex & & & & & & & $<0.0001$ \\
\hline Female & 47.5 (769) & $74.7(180)$ & $55.4(372)$ & $85.7(24)$ & $57.5(42)$ & 52.7 (1387) & \\
\hline Male & $52.5(851)$ & $25.3(61)$ & $44.6(299)$ & $14.3(4)$ & $42.5(31)$ & $47.3(1246)$ & \\
\hline Age groups, years & & & & & & & 0.005 \\
\hline $20-40$ & $31.0(503)$ & $32.9(79)$ & $35.3(236)$ & $25.0(7)$ & $35.1(26)$ & $32.4(851)$ & \\
\hline $41-61$ & $52.7(854)$ & $55.0(132)$ & $52.0(348)$ & $64.3(18)$ & $36.5(27)$ & $52.4(1379)$ & \\
\hline $61-76$ & $16.2(263)$ & $12.1(29)$ & $12.7(85)$ & $10.7(3)$ & $28.4(21)$ & $15.2(401)$ & \\
\hline Age, mean (SD) & $47.2(12.3)$ & $46.1(12.3)$ & $46.0(12.4)$ & $48.3(10.4)$ & $50.0(13.2)$ & & \\
\hline Level of high education ${ }^{c}$ & & & & & & & $<\mathbf{0 . 0 0 0 1}$ \\
\hline None higher & $1.6(26)$ & $5.0(12)$ & $1.9(13)$ & $0.0(0)$ & $0.0(0)$ & $1.9(51)$ & \\
\hline Short higher ( $<3$ years) & $29.0(471)$ & $35.0(84)$ & $30.5(204)$ & $0.0(0)$ & $0.0(0)$ & $28.8(759)$ & \\
\hline Medium higher ( $3-4$ years) & $30.9(502)$ & $30.0(72)$ & $34.6(232)$ & $0.0(0)$ & $0.0(0)$ & $30.6(806)$ & \\
\hline Long higher ( $>4$ years) & $34.1(554)$ & $24.2(58)$ & $29.3(196)$ & $100.0(28)$ & $100.0(74)$ & $34.5(910)$ & \\
\hline Other education & $4.3(70)$ & $5.8(14)$ & $3.7(25)$ & $0.0(0)$ & $0.0(0)$ & $4.1(109)$ & \\
\hline Marital status & & & & & & & $<\mathbf{0 . 0 0 0 1}$ \\
\hline Married/cohabiting & $69.6(1128)$ & $56.7(136)$ & $62.2(417)$ & $82.1(23)$ & $79.5(58)$ & $66.9(1762)$ & \\
\hline Partnership & $9.9(161)$ & $12.5(30)$ & $17.3(116)$ & $3.6(1)$ & $4.1(3)$ & $11.8(311)$ & \\
\hline Single & $20.5(332)$ & $30.8(74)$ & $20.6(138)$ & $82.1(4)$ & $16.4(12)$ & $21.3(560)$ & \\
\hline Children & & & & & & & 0.23 \\
\hline Yes & $46.2(749)$ & $42.7(103)$ & $48.1(322)$ & $64.3(18)$ & $47.3(35)$ & 46.6 (1227) & \\
\hline No & $53.8(871)$ & $57.3(138)$ & $51.9(348)$ & $35.7(10)$ & $52.7(39)$ & $53.4(1406)$ & \\
\hline
\end{tabular}

Note: Values that were significant at $5 \%$ are shown in bold type.

a $n$ varies because of missing data.

b $\chi^{2}$.

c Children must receive 10 years of compulsory education in Denmark. 
Table 2

Personal experience with genetic testing, genomic analysis, and genetic research.

\begin{tabular}{|c|c|c|c|c|c|c|c|}
\hline $\mathrm{N}$ & $\begin{array}{l}\text { Blood donors } \\
\text { Yes \% }(\mathrm{n})\end{array}$ & $\begin{array}{l}\text { Persons with mental disorder } \\
\text { Yes \% (n) }\end{array}$ & $\begin{array}{l}\text { Relatives } \\
\text { Yes \% (n) }\end{array}$ & $\begin{array}{l}\text { Clinical geneticists } \\
\text { Yes \% (n) }\end{array}$ & $\begin{array}{l}\text { Psychiatrists } \\
\text { Yes \% (n) }\end{array}$ & $\begin{array}{l}\text { Total } \\
\text { Yes \% (n) }\end{array}$ & P-value ${ }^{a}$ \\
\hline \multicolumn{8}{|c|}{ Have you personally had either genetic testing or genomic analysis done? } \\
\hline 2633 & $4.4(71)$ & $6.2(15)$ & $6.3(42)$ & $10.7(3)$ & $9.5(7)$ & $5.2(138)$ & 0.07 \\
\hline \multicolumn{8}{|c|}{ Are you a research participant in a biobank? } \\
\hline 2626 & $27.6(447)$ & $12.9(31)$ & $25.1(167)$ & $21.4(6)$ & $9.5(7)$ & $25.1(658)$ & $<\mathbf{0 . 0 0 0 1}$ \\
\hline \multicolumn{8}{|c|}{ Have you or your family ever been (or are currently) a research participant in a genetic research project? ${ }^{\mathrm{b}}$} \\
\hline 2635 & $9.6(155)$ & $7.5(18)$ & $12.1(81)$ & $10.7(3)$ & $12.2(9)$ & $10.1(266)$ & 0.04 \\
\hline
\end{tabular}

Note: Values that were significant at $5 \%$ are shown in bold type.

a $\chi^{2}$.

b Don't know \% (n): 24.8 (402); 23.7 (57); 26.7 (179); 10.7 (3); 13.5(10).

Table 3

Attitudes toward consent procedure.

\begin{tabular}{|c|c|c|c|c|}
\hline & $\mathrm{N}$ & Yes \% (n) & $\mathrm{OR}_{\mathrm{adj}}(95 \% \mathrm{CI})^{\mathrm{a}}$ & P-value \\
\hline \multicolumn{5}{|c|}{ Prior to a whole genome study, the research participant should have agreed to the specific aim of the study? } \\
\hline \multicolumn{5}{|c|}{2545} \\
\hline Blood donors & & $92.4(1449)$ & 1.0 & \\
\hline Persons with mental disorder & & $93.6(218)$ & $0.93(0.52-1.64)$ & 0.97 \\
\hline Relatives & & $93.0(601)$ & $1.01(0.70-1.45)$ & 0.97 \\
\hline Clinical geneticists & & $100(28)$ & $-(-)^{\mathrm{b}}$ & 0.97 \\
\hline Psychiatrists & & $90.0(63)$ & $0.72(0.31-1.68)$ & 0.96 \\
\hline Total & & 92.7 (2359) & & \\
\hline \multicolumn{5}{|c|}{$\begin{array}{l}\text { In a whole genome study, research participants could update and change what information they choose to receive. Do you find it acceptable to have such a } \\
\text { 'dynamic consent' process? }\end{array}$} \\
\hline \multicolumn{5}{|c|}{2406} \\
\hline Blood donors & & $84.7(1270)$ & 1.0 & \\
\hline Persons with mental disorder & & $88.3(188)$ & $1.29(0.82-2.02)$ & 0.34 \\
\hline Relatives & & $86.0(520)$ & $1.06(0.81-1.40)$ & 0.84 \\
\hline Clinical geneticists & & $92.3(24)$ & $1.96(0.45-8.46)$ & 0.28 \\
\hline Psychiatrists & & $71.4(45)$ & $0.42(0.23-0.76)$ & 0.001 \\
\hline Total & & $85.1(2047)$ & & \\
\hline
\end{tabular}

Note: Values that were significant at $5 \%$ are shown in bold type.

a Adjusted for parenthood, gender, age, educational level, and marital status.

$\mathrm{b}$ Does not compute due to uniform answers.

Table 4

Delivery of genomic information.

\begin{tabular}{|c|c|c|c|c|c|c|c|}
\hline & $\begin{array}{l}\text { Blood donors } \\
\%(n)\end{array}$ & $\begin{array}{l}\text { Persons with mental disorder } \\
\%(\mathrm{n})\end{array}$ & $\begin{array}{l}\text { Relatives } \\
\%(n)\end{array}$ & $\begin{array}{l}\text { Clinical geneticists } \\
\%(\mathrm{n})\end{array}$ & $\begin{array}{l}\text { Psychiatrists } \\
\%(n)\end{array}$ & $\begin{array}{l}\text { Total } \\
\%(n)\end{array}$ & P-value ${ }^{a}$ \\
\hline \multicolumn{7}{|c|}{$\begin{array}{l}\text { We assume that a research participant has given consent to receive genomic information relating to serious or life-threatening conditions. How should } \\
\text { this information be delivered? }\end{array}$} & 0.19 \\
\hline Indirect contact & $3.2(52)$ & $1.7(4)$ & $3.0(20)$ & $0(0)$ & $5.4(4)$ & $3.0(80)$ & \\
\hline Direct contact & $70.0(1136)$ & $65.4(157)$ & $70.2(471)$ & $75.0(21)$ & $63.5(47)$ & $69.5(1832)$ & \\
\hline Indirect and direct contact & $25.5(414)$ & $30.4(73)$ & $25.3(170)$ & $17.9(5)$ & $29.7(22)$ & $26.0(684)$ & \\
\hline Don't know & $1.3(21)$ & $2.5(6)$ & $1.5(10)$ & $7.1(2)$ & $1.4(1)$ & $1.5(40)$ & \\
\hline \multicolumn{8}{|c|}{$\begin{array}{l}\text { We assume that a research participant has given consent to receive genomic information relating to non-serious or not-life-threatening conditions. How should } \\
\text { this information be delivered? }\end{array}$} \\
\hline Indirect contact & $48.2(780)$ & $47.5(113)$ & $48.4(324)$ & $21.4(6)$ & $49.3(36)$ & 47.9 (1259) & 0.01 \\
\hline Direct contact & $28.8(466)$ & $26.9(64)$ & $25.6(171)$ & $53.6(15)$ & $21.9(16)$ & $27.9(732)$ & \\
\hline Indirect and direct contact & $21.0(340)$ & $23.5(56)$ & $23.5(157)$ & $17.9(5)$ & $21.9(16)$ & $21.8(574)$ & \\
\hline Don't know & $2.0(33)$ & $2.1(5)$ & $2.5(17)$ & $7.1(2)$ & $6.9(5)$ & $2.4(62)$ & \\
\hline
\end{tabular}

a $\chi^{2}$ Note: Values that were significant at $5 \%$ are shown in bold type.

participants to determine which information they should receive. This could be viewed as an expression of autonomous will and illustrates that potential research subjects do not see themselves as passive research subjects. At the same time, it may also reflect a perception of, what is expected of a responsible person. However, these findings illustrate that the stakeholders want to be more actively involved and consider consent as a reciprocal transaction between the involved subjects and the researchers in the project.
We found that psychiatrists were generally more negatively inclined towards the dynamic consent than the other stakeholder groups. Psychiatrists might have more concerns about the information that can be returned through dynamic consent than, for example, persons with mental disorders tend to have. Psychiatrists may find that genomic information received from research does not provide any real practical advantage for the health and treatment of their patients. The more negative attitude 
among psychiatrists could also be related to their lack of skills, experience and expertise to interpreting and explaining complex genomic information. Psychiatrists may not have sufficient genomic knowledge to help patients cope with the genomic findings.

We also found that only few blood donors realized that they had, in fact already consented to be research participants in a biobank and in a genetic research project. The blood donors had very little knowledge about the use of their own blood samples. All the blood donors who participated in our survey are part of the Danish Blood Donor Study, and they have all given a broad informed consent to participate in a biobank for research. However, the blood donors have not given a specific consent for genome sequencing [38]. A previous study has shown that many donors do not read the offered information and that the decision to participate in research is usually not based on knowledge of the purpose of the genetic research project. Rather the willingness to participate in research is a personal interest in attaining knowledge of their own health and a sense of duty to help others [39]. Although protecting research subjects against harm and respecting their autonomy is important, the findings from this study and a previous study [39] also show that participants are not always fully aware of what exactly they have signed up for. This raises vital questions about the validity of the informed consent but also indicates that the decision to participate in research does not specifically rest on an expectation to receive individual genomic information. Rather, the decision seems to be based on an intention to contribute to research that may help others in the future.

However, if research subjects are generally unaware and not interested in what they have consented to, how can we secure their interest in giving a specific consent and then "dynamically" decide which information they want to receive? Some researchers have suggested development of a new model for informed consent specifically for the return of incidental findings in genomic research [6]. Additionally, some researchers are working on a dynamic consent platform to provide recruitment of participants, collection of informed consent, and ongoing communication between researchers and participants [20]. With technological advancements, it must be possible to find a way to obtain and manage a dynamic consent. However, it is uncertain if research subjects using for example dynamic consent platforms are more aware of what they have signed up for and pay more attention to the information than research subjects using a traditional platform of providing an informed consent.

\subsection{Delivery of genomic information}

Our analyses illustrate that the majority of the stakeholders prefer to receive genomic information related to serious or lifethreatening conditions through direct contact with a health professional. Direct contact are much more costly and timeconsuming than a letter, but a direct contact ensure fewer misinterpretations of results. A previous study of individuals affected by mental disorder $(\mathrm{N}=33)$ and unaffected family members $(\mathrm{N}=22)$ showed that the respondents preferred to receive genetic findings (for any health condition) from genome sequencing studies by letter, telephone, or email [26].

Our study show that the respondents expect researchers and health professionals to collaborate as they prefer to receive genomic information related to serious or life-threatening conditions through direct contact with a health professional. The health professionals are expected to explain the research findings and help the respondents to cope with the findings. Most psychiatrists do not have sufficient genomic knowledge to help patients interpret genomic findings, and many genomic researchers have not previously had direct contact with research subjects.
Therefore, both psychiatrists and researchers may face challenges in framing meaningful explanations for research subjects. This highlights the importance of close collaboration with health professionals such as clinical geneticists, who are trained through their education and clinical work to return and explain genomic data to patients and their relatives. Importantly, our results illustrate that persons with a mental disorder, relatives and psychiatrists do no differ in their attitudes from blood donors. They attribute return of findings roughly the same value. Our study thus contributes with new original knowledge regarding of stakeholders in psychiatry.

\subsection{Strengths and limitations}

A key strength of this study is the relatively large number of stakeholders who participated and provided us with thorough information. Persons with mental disorders are a vulnerable group who are difficult to recruit into trials [40]. However, this study accessed and recruited the hard-to-reach group. Furthermore, it is a strength that we included different groups of stakeholders with strong relations to psychiatry and genetics; both with personal experience and professional experience.

The recruitment strategies were both a strength and a limitation. A web-based survey is known as a good method to recruit hard-to-reach groups [41,42]. At the same time, using a web-based survey requires the respondents to be familiar with smartphones, tables, laptops, or computers, and this may have excluded potential respondents without these skills or without access to such technical equipment or to the internet such as elderly people. But the web-based survey did not provide any details on non-responders. Although the respondents were recruited through a diversity of sources, all participants entered the studies on a voluntary basis. Therefore, it is likely that the included stakeholders are more homogeneous and more in favor of genomic research than potential respondents who did not participate. Still, as the survey was freely available online, it may also have attracted more responses from people with polarised views [43].

According to the Danish Health Data Authority, there were 36 clinical geneticists and 1125 psychiatrists in total in Denmark as of 31 December 2013 [44]. Very few psychiatrists responded whereas almost all clinical geneticists responded to the survey. One hypothesis explaining the non-response among psychiatrists is the relation between outcome of interest and likelihood to participate [45]. However, it is difficult to know why psychiatrists was not interested in participating in the study. If the underlying mechanism for not being interested is negative beliefs about genomic research, this would have caused an underestimation of the negative attitudes toward genomic research. This potential selection bias implies that the stakeholders included in this study are not entirely representative of the general population. It would thus be important to validate the results by using a mixture of methods with the expectation that qualitative interviews would elucidate the results and perhaps include the views of stakeholders who did not participate in the survey.

Another limitation is the hypothetical nature of the questions as these responses may not truly reflect actual-life behavior [46]. Lastly, it is a limitation that we did not explore the respondents' attitudes towards the use of different models of consent in genomic research, for example broad consent, and/or presumed consent. This issue remains to be investigated in future studies.

\section{Conclusion}

In this study, potential stakeholders in psychiatric genomic research were invited to express their views on and attitudes 
towards consenting procedures and delivery of incidental findings. Our study provides new perspectives on the attitudes among stakeholders in psychiatric genomic research. We found that the stakeholders did not want to be seen as passive research subjects. Rather, they preferred to be actively involved and provided with the opportunity to give a specific informed consent and regularly decide in a 'dynamic' manner which information they wanted to receive.

An important finding is the general support for delivery of genomic information related to serious or life-threatening conditions through direct contact with a health professional. This highlights the importance of close collaboration between different groups of health professionals to ensure that genomic research information can be returned and explained to research subjects in a competent manner. Finally, persons with mental disorders and relatives do not differ in their attitudes from other members of the public. The stakeholders attribute consenting procedures and delivery of incidental findings roughly the same value.

Today no consensus currently exists on the best way to obtain the informed consent and deliver genomic research findings. This study offers valuable insight and this new knowledge may be used in future studies and programs aiming to provide more pioneering ways of obtaining meaningful consent and better feedback strategies.

\section{Funding sources}

We would like to acknowledge the Deciphering Developmental Disorders (DDD) study for funding the films that were used in this research. The DDD study presents independent research commissioned by the Health Innovation Challenge Fund (grant number: HICF-1009-003), a parallel funding partnership between the Wellcome Trust and the Department of Health, Cambridge, UK. This study was financially supported by the Lundbeck Foundation Initiative for Integrative Psychiatric Research (iPSYCH), Denmark (grant number: R155-2014-1724) and Aarhus University. The funding sources were not involved in the study design, data collection and analysis, writing of the manuscript or decision regarding publication.

\section{Declaration of conflicting interests}

The authors declares that there is no conflict of interest.

\section{Acknowledgments}

The authors would like to thank Associate Professor Aaro Mikael Tupasela for valuable constructive comments on an earlier draft of this article.

\section{References}

[1] Doherty J.L., Owen MJ. Genomic insights into the overlap between psychiatric disorders: implications for research and clinical practice. Genome Med 2014;6:29, doi:http://dx.doi.org/10.1186/gm546.

[2] McGuffin P, Southwick L. Fifty years of the double helix and its impact on psychiatry. Aust N Z J Psychiatry 2003;37:657-61, doi:http://dx.doi.org/ 10.1111/j.1440-1614.2003.01266.x.

[3] Kavanagh DH, Tansey KE, O'Donovan MC, Owen MJ. Schizophrenia genetics: emerging themes for a complex disorder. Mol Psychiatry 2015;20:72-6, doi: http://dx.doi.org/10.1038/mp.2014.148.

[4] Hoop JG. Ethical considerations in psychiatric genetics. Harv Rev Psychiatry 2008;16:322-38, doi:http://dx.doi.org/10.1080/10673220802576859.

[5] Pedersen CB, Bybjerg-Grauholm J, Pedersen MG, Grove J, Agerbo E, BækvadHansen M, et al. The iPSYCH2012 case-cohort sample: new directions for unravelling genetic and environmental architectures of severe mental disorders. Mol Psychiatry 2017, doi:http://dx.doi.org/10.1038/mp.2017.196.
[6] Appelbaum PS, Parens E, Waldman CR, Klitzman R, Fyer A, Martinez J, et al. Models of consent to return of incidental findings in genomic research. Hastings Cent Rep 2014;44:22-32, doi:http://dx.doi.org/10.1002/hast.328.

[7] Ebbesen M, Sundby A, Pedersen FS, Andersen S. A philosophical analysis of informed consent for whole genome sequencing in biobank research by use of Beauchamp and Childress' four principles of biomedical ethics. J Clin Res Bioeth 2015;06, doi:http://dx.doi.org/10.4172/2155-9627.1000244.

[8] Parens E, Appelbaum P, Chung W. Incidental Findings in the Era of Whole Genome Sequencing? Hast Cent Rep 2013;43:16-9, doi:http://dx.doi.org/ 10.1002/hast.189.

[9] Kaye J, Whitley EA, Lund D, Morrison M, Teare H, Melham K. Dynamic consent: a patient interface for twenty-first century research networks. Eur J Hum Genet 2015;23:141-6, doi:http://dx.doi.org/10.1038/ejhg.2014.71.

[10] Knoppers BM, Joly Y, Simard J, Durocher F. The emergence of an ethical duty to disclose genetic research results: international perspectives. Eur J Hum Genet 2006;14:1170-8, doi:http://dx.doi.org/10.1038/sj.ejhg.5201690.

[11] McGuire AL, Lupski JR. Personal genome research: what should the participant be told? Trends Genet 2010;26:199-201, doi:http://dx.doi.org/10.1016/j. tig.2009.12.007.

[12] O'Daniel J, Haga SB. Public perspectives on returning genetics and genomics research results. Public Health Genomics 2011;14:346-55, doi:http://dx.doi. org/10.1159/000324933.

[13] Steinsbekk KS, Kåre Myskja B, Solberg B. Broad consent versus dynamic consent in biobank research: Is passive participation an ethical problem? Eur Hum Genet 2013, doi:http://dx.doi.org/10.1038/ejhg.2012.282.

[14] Viberg J, Segerdahl P, Langenskiöld S, Hansson MG. Freedom of choice about incidental findings can frustrate participants' true preferences. Bioethics 2015;203-9, doi:http://dx.doi.org/10.1111/bioe.12160.

[15] Ryan KA, De Vries RG, Uhlmann WR, Roberts JS, Gornick MC. Public's views toward return of secondary results in genomic sequencing: it's (Almost) all about the choice. J Genet Couns 2017;1-16, doi:http://dx.doi.org/10.1007/ s10897-017-0095-6.

[16] Harris J. Scientific research is a moral duty. J Med Ethics 2005;31:242-8, doi: http://dx.doi.org/10.1136/jme.2005.011973.

[17] World Medical Association. WMA Declaration of Helsinki - Ethical Principles for Medical Research Involving Human Subjects - WMA - The World Medical Association n.d. https://www.wma.net/policies-post/wma-declaration-ofhelsinki-ethical-principles-for-medical-research-involving-human-subjects/.

[18] Hoeyer K. Informed consent: the making of a ubiquitous rule in medical practice. Organization 2009;16:267-88, doi:http://dx.doi.org/10.1177/ 1350508408100478.

[19] Wadmann S. Informeret samtykke i kliniske forsøg: teknikaliteter, tillid og tætte relationer. Etikk Praksis Nord J Appl Ethics 2013;7:31-46.

[20] Budin-Ljøsne I, Teare HJA, Kaye J, Beck S, Bentzen HB, Caenazzo L, et al. Dynamic Consent: a potential solution to some of the challenges of modern biomedical research. BMC Med Ethics 2017;18:, doi:http://dx.doi.org/10.1186 s12910-016-0162-9.

[21] Hoeyer K. The ethics of research biobanking: a critical review of the literature Biotechnol Genet Eng Rev 2008;25:429-52, doi:http://dx.doi.org/10.5661/ bger-25-429.

[22] Hoeyer KL. Size matters : the ethical, legal and social issues surrounding largescale genetic biobank initiatives. Nor Epidemiol 2012;21:211-20.

[23] Bunnik EM, de Jong A, Nijsingh N, de Wert GMWR. The new genetics and informed consent: differentiating choice to preserve autonomy: the new genetics and informed consent: differentiating choice to preserve autonomy. Bioethics 2013;27:348-55, doi:http://dx.doi.org/10.1111/bioe.12030.

[24] Kaye J, Kanellopoulou N, Hawkins N, Gowans H, Curren L, Melham K. Can I access my personal genome? The current legal position in the UK. Med Law Rev 2014;22:64-86, doi:http://dx.doi.org/10.1093/medlaw/fwt027.

[25] Solberg B, Steinsbekk KS. Managing incidental findings in population based biobank research. J Epidemiol 2012;21:195-202 2012:195-202..

[26] Bui ET, Anderson NK, Kassem L, McMahon FJ. Do participants in genome sequencing studies of psychiatric disorders wish to Be informed of their results? A survey study. PLoS One 2014;9:e101111, doi:http://dx.doi.org/ 10.1371/journal.pone.0101111.

[27] Yu J-H Harrell TM, Jamal SM, Tabor HK, Bamshad MJ. Attitudes of genetics professionals toward the return of incidental results from exome and wholegenome sequencing. Am J Hum Genet 2014;95:77-84, doi:http://dx.doi.org/ 10.1016/j.ajhg.2014.06.004.

[28] Middleton A, Wright CF, Morley KI, Bragin E, Firth HV, Hurles ME, et al Potential research participants support the return of raw sequence data. J Med Genet 2015;52:571-4, doi:http://dx.doi.org/10.1136/jmedgenet-2015-103119.

[29] Middleton A, Morley KI, Bragin E, Firth HV, Hurles ME, Wright CF, et al Attitudes of nearly 7000 health professionals, genomic researchers and publics toward the return of incidental results from sequencing research. Eur J Hum Genet 2016;24:21-9, doi:http://dx.doi.org/10.1038/ejhg.2015.58.

[30] Sundby A, Boolsen MW, Burgdorf KS, Ullum H, Hansen TF, Middleton A, et al. Stakeholders in psychiatry and their attitudes toward receiving pertinent and incident findings in genomic research. Am J Med Genet A 2017;173:2649-58, doi:http://dx.doi.org/10.1002/ajmg.a.38380.

[31] Klitzman R, Appelbaum PS, Fyer A, Martinez J, Buquez B, Wynn J, et al. Researchers' views on return of incidental genomic research results: qualitative and quantitative findings. Genet Med 2013;15:888-95, doi:http:// dx.doi.org/10.1038/gim.2013.87.

[32] Middleton A, Bragin E, Morley KI, Parker M. Online questionnaire development: using film to engage participants and then gather attitudes 
towards the sharing of genomic data. Soc Sci Res 2013;211-23, doi:http://dx. doi.org/10.1016/j.ssresearch.2013.12.004.

[33] Middleton A, Bragin E, Parker M. Finding people who will tell you their thoughts on genomics-recruitment strategies for social sciences research. J Community Genet 2014;291-302, doi:http://dx.doi.org/10.1007/s12687-014-0184-2.

[34] Sundby A, Boolsen MW, Burgdorf KS, Ullum H, Hansen TF, Mors O. Attitudes of stakeholders in psychiatry towards the inclusion of children in genomic research. Hum Genomics 2018;12:, doi:http://dx.doi.org/10.1186/s40246-018-0144-8.

[35] The Danish Blood Donor Study. The danish blood donor study. 2016. http:// www.dbds.dk/defaultUK.htm.

[36] Pedersen OB, Erikstrup C, Kotzé SR, Sørensen E, Petersen MS, Grau K, et al. The Danish Blood Donor Study: a large, prospective cohort and biobank for medical research. Vox Sang 2012;102:, doi:http://dx.doi.org/10.1111/j.14230410.2011.01553.x 271-271.

[37] SAS Institute Inc. SAS $($ 9.4. 100 SAS Campus Drive Cary, NC 27513-2414, USA: Cary, USA.

[38] Det Danske Bloddonorstudie. Samtykkeerklæring for projektet: Det danske bloddonorstudie. [Informed consent for the project: The Danish Blood Donor Study] 2010. http://www.dbds.dk/samtykkeerkl\%C3\%A6ring.htm.

[39] Hoeyer K. Science is really needed-that's all I know": informed consent and the non-verbal practices of collecting blood for genetic research in northern Sweden. New Genet Soc 2003;22:229-44, doi:http://dx.doi.org/10.1080/ 1463677032000147199.
[40] Jørgensen R, Munk-Jørgensen P, Lysaker PH, Buck KD, Hansson L, Zoffmann V. Overcoming recruitment barriers revealed high readiness to participate and low dropout rate among people with schizophrenia in a randomized controlled trial testing the effect of a Guided Self-Determination intervention. BMC Psychiatry 2014;14:, doi:http://dx.doi.org/10.1186/1471-244X-14-28.

[41] Frippiat D, Marquis N, Wiles-Portier E. Web surveys in the social sciences: an overview. Popul Engl Ed 2002;65:285-311 2002-2010.

[42] Barratt MJ, Ferris JA, Hidden Populations Lenton S. Online purposive sampling, and external validity: taking off the blindfold. Field methods 2015;27:3-21, doi:http://dx.doi.org/10.1177/1525822X14526838.

[43] Heaton TJ, Chico V. Attitudes towards the sharing of genetic information with at-risk relatives: results of a quantitative survey. Hum Genet 2016;135:10920, doi:http://dx.doi.org/10.1007/s00439-015-1612-z.

[44] Sundhedsdatastyrelsen [The danish health data authority]. Arbejdsstyrken af sundhedsuddannede. 2016. http://esundhed.dk/sundhedsaktivitet/ arbejdsmarked/arbejdsstyrke/Sider/Arbejdsstyrken-af-sundhedsuddannede. aspx.

[45] Galea S, Tracy M. Participation rates in epidemiologic studies. Ann Epidemiol 2007;17:643-53, doi:http://dx.doi.org/10.1016/j.annepidem.2007.03.013.

[46] Persky S, Kaphingst KA, Condit CM, McBride CM. Assessing hypothetical scenario methodology in genetic susceptibility testing analog studies: a quantitative review. Genet Med 2007;9:727-38, doi:http://dx.doi.org/ 10.1097/GIM.0b013e318159a344. 